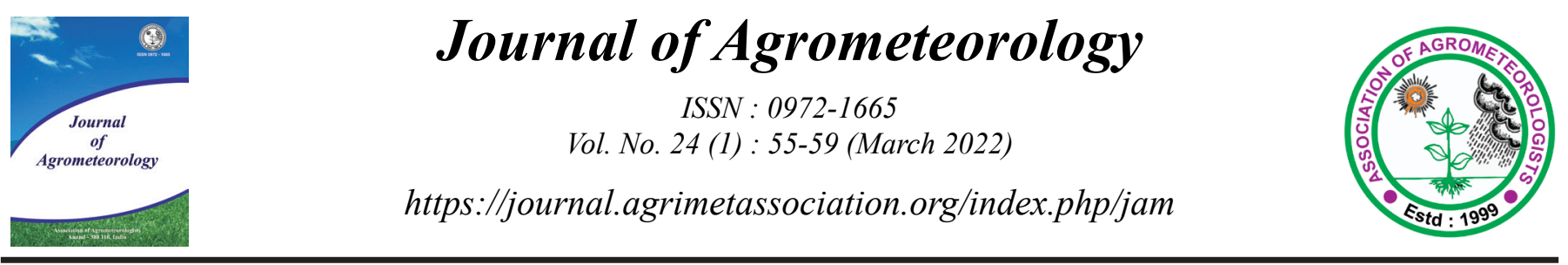

Research Paper

\title{
Epidemiological models based on meteorological variables to forewarn Alternaria blight of rapeseed-mustard
}

\author{
M.S. YADAV ${ }^{*}$, AMRENDER KUMAR ${ }^{2}$, C. CHATTOPADHYAY ${ }^{3}$ and D.K. YADAVA ${ }^{4}$ \\ 1 ICAR-National Research Centre for Integrated Pest Management, New Delhi, India \\ ${ }^{2}$ ICAR-Indian Agricultural Research Institute, New Delhi, India \\ ${ }^{3}$ ICAR-Indian Institute of Agricultural Biotechnology, Ranchi, India \\ ${ }^{4}$ Indian Council of Agricultural Research, Krishi Bhawan, New Delhi, India \\ *Corresponding author email:ms.yadav@icar.gov.in
}

\begin{abstract}
Alternaria blight [Alternaria brassicae (Berk.) Sacc.] is one of the most widespread and harmful maladies of rapeseed-mustard, causing yield loss up to 47 per cent. Meteorological parameters especially temperature, relative humidity and bright sunshine hours play major role in the development of Alternaria blight disease. Infection by the pathogen is highly influenced by meteorological conditions. A well-tested model based on meteorological variables is an efficient tool for forewarning this disease. Epidemiology of Alternaria blight of brassicas was investigated based on long term data during 2003-2018 crop seasons on the disease severity and meteorological variables, which was validated with data for two subsequent years. During this study, meteorological variable-based regression model of forewarning was developed for maximum severity (\%) of Alternaria blight on leaves and pods for three locations viz., New Delhi, Hisar (Haryana) and Mohanpur (West Bengal)] in India. Validation of the forewarning models for maximum severity (\%) of Alternaria blight proved the efficiency of the targeted forecasts.
\end{abstract}

Keywords: Epidemiological models, meteorological variables, Alternaria blight, forewarning, Brassica

The onset of a disease and growth of its causal pathogen is strongly dependent on host-pathogen interaction with meteorological variables (Chattopadhyay et al., 2015). This leads to studies on weather-disease interaction of different crops worldwide. Meteorological variables-based forewarning of major diseases, especially the time of onset, time of peak and level of severity, is useful to farmers to decide on crop protection. Rapeseed-mustard crops are gaining importance worldwide due to its advantage over other oilseed crops viz., higher yield potential, low moisture requirement, higher return at low cost of production, wider adaptability for various farming conditions, etc. This crop is gaining wide acceptance among the farmers because of adaptability for both irrigated as well as rainfed areas and suitability for sole as well as mixed cropping. Besides, it offers higher return with low cost of production and low water requirement. Rapeseed-mustard is the third most important oilseed crop in terms of acreage and production after soybean and oil palm in the world and occupies second position after soybean in India. India has produced 10.11 MT of rapeseed-mustard from 6.79 mha of land with average productivity of $1489 \mathrm{~kg} / \mathrm{ha}$ during the 2020-21 season (GoI, 2021).
Rapeseed-mustard is contributing approximately 28 per cent of India's total oilseed production. The production and productivity of rapeseed-mustard in India are comparatively low as compared to the world average due to the biotic and abiotic constraints. The loss in oilseed crops due to biotic stresses is about 19.9 per cent, of which diseases contribute a major share. Among the biotic stresses, Alternaria blight is the most common, widespread and destructive disease caused by Alternaria brassicae (Berk.) Sacc. Singh et al. (2009) reported the influence of meteorological parameters on incidence and development of white rust and Alternaria blight in mustard (Brassica juncea). Kumar et al. (2010) also reported effect of projected climate change on mustard (B. juncea). Depending upon the prevailing weather conditions, Alternaria blight infects all aboveground parts of plants that lead to yield losses up to 47 per cent (Chattopadhyay et al., 2015). The onset and spread of a crop disease is regulated by short-term meteorological anomalies during a crop season. Changing disease scenario due to climate change has necessitated the urgency for studies on forewarning models that can predict the severity of important diseases in real-field conditions. Meteorological conditions are important factors in the severity of

Article info - DOI: https://doi.org/10.54386/jam.v24i1.782

Received: 25 October 2021; Accepted: 29 December 2021; Published online: 11 February 2022

This work is licenced under a Creative Common Attribution4.0International licence@Author(s),Publishing right@Association of Agrometeorologists 
Alternaria blight of rapeseed-mustard. Efficient, economical and environment friendly management of Alternaria blight can be obtained through the knowledge of its timing of attack in relation to weather factors, which may enable prediction of its occurrence to allow growers to take timely action in an efficient manner. While recommending management strategies under Jorhat conditions, Talukdar et al. (2017) reported that early sowing of rapeseed could effectively help in reducing the severity of Alternaria blight. The meteorological-based modeling for early forewarning of disease may provide appropriate tools for predicting disease status (Kumar, 2013) that may further enable in guiding the farmers for taking timely protection measures. Preliminary work indicates effects of temperature, relative humidity $(\mathrm{RH})$ and sunshine hours on occurrence of the blight on the rapeseed-mustard. Earlier researchers (Yadav et al., 2010; Mahapatra and Das, 2014) have studied the empirical relationship of Alternaria blight disease with environmental factors. However, they provide no insight into quantitative forewarning of Alternaria blight. Earlier workers (Awasthi and Kolte, 1994; Dang et al., 1995) reported that a combined effect of humidityrainfall and minimum temperature accounted for more than 98 per cent variation in Alternaria blight severity on leaves as well as on pods of rapeseed-mustard. Initiation of Alternaria blight disease on leaves of mustard occurs between 45 and 75 days after sowing (DAS). Initiation of the disease on pods occurs between 67 and 142 DAS, highest being 99 DAS. Meteorological conditions such as temperature, relative humidity $(\mathrm{RH})$, rainfall and bright sunshine hours are exceptionally important factors in the severity of Alternaria blight on rapeseed-mustard. Thus, a technique based on relatively smaller number of manageable variables and at the same time taking care of distribution of meteorological factors, meteorological indices were obtained which were used as predictors for model development. Infection of host by pathogen for causing disease is dependent upon meteorological factors and suitable cropdisease-weather relationship can be developed to assess the risk of the disease (Yadav et al., 2010). Hence, the present multi-locational study was undertaken to develop meteorological variable dependent epidemiological models for quantitative and early forewarning in Alternaria blight of rapeseed- mustard.

\section{MATERIALS AND METHODS}

\section{Field experiments}

Selection of centers for study was based on the area of crop in India and economic importance of Alternaria blight as a major constraint in cultivation of rapeseed-mustard in the region. All experiments relied entirely on natural infection of Alternaria blight. Field trials were sown in the month of November in plots of size $5 \mathrm{~m} \times 3 \mathrm{~m}$ with spacing of $30 \mathrm{~cm} \times 10 \mathrm{~cm}$ at New Delhi $\left(28^{\mathrm{O}} 39^{\prime} \mathrm{N} ; 7^{\mathrm{O}} 13^{\prime} \mathrm{E}\right)$ from $2006-07$ to $2017-18$, Hisar $\left(29^{\mathrm{O}} 14^{\prime} \mathrm{N}\right.$; $\left.75^{\circ} 70^{\prime} \mathrm{E}\right)$, Haryana from 2003-04 to 2016-17 and Mohanpur $\left(22^{\mathrm{O}} 57^{\prime} \mathrm{N} ; 88^{\mathrm{O}} 20 \mathrm{E}\right.$ ), West Bengal from $2005-06$ to $2015-16$ in postrainy season with different cultivars viz., cv. Rohini for Hisar and New Delhi and cv. YSB-9 for Mohanpur along with recommended nitrogen and phosphorus for different agro-ecological zones of the country. Severity (\%) on leaves was observed at 75 and 100 days after sowing at Mohanpur, Hisar and Delhi, respectively, while severity (\%) on pods was observed 20 days before harvest at
Hisar and Mohanpur. Observations were recorded on 10 randomly tagged plants of crop in each experimental plot on leaves and pods following scale of Conn et al. (1990). Data of meteorological variables viz., temperatures (maximum and minimum), relative humidity (morning and afternoon) and bright sunshine hours were obtained for the specified period from respective meteorological observatories situated near experimental field.

\section{Development of epidemiological models for Alternaria blight}

Meteorological parameters-based forewarning models were developed for maximum severity (\%) of disease on leaves and pods and validation of the forewarning models was undertaken to prove the targeted forecasts in last two years or the subsequent crop seasons. Historical disease data and meteorological data (temperature, relative humidity, rainfall and bright sunshine hours) were utilized for model development and their validation for the last two seasons. Meteorological indices were obtained and used as predictors for model development. In this type of model, for each weather variable two indices were developed i.e., one as a simple total of values of weather variables in different weeks and weighted total, weighted values being used for determining correlation coefficients between variable to forecast and weather variable in respective weeks. Hence, development of models for quantitative data has been attempted. The first index represents total amount of different weather variables received by the crop during the period under consideration while the other one takes care of distribution of weather variable with special reference to its importance in different weeks in relation to the variable to forecast. The simplest way to solve the problem is to take weighted accumulation of meteorological variables, giving weights according to their importance in different times. Similarly, with the combined effects of weather variables, weather indices were developed as weighted accumulations of product of weather variable (taking two at a time), weights being correlation coefficients between variable to forecast and product of weather variables considered in respective weeks (Yadav et al., 2016; Chattopadhyay et al., 2021).

The form of the model was

$$
Y=a_{0}+\sum_{i=1}^{p} \sum_{j=0}^{1} a_{j} Z_{j}+\sum_{i \neq 1}^{p} \sum_{j=0}^{1} b_{i^{\prime} j} Z_{i}{ }^{\prime} j
$$

where

$$
\begin{aligned}
& Z_{\mathrm{ij}}=\sum_{\mathrm{w}=\mathbf{n}_{\mathbf{1}}}^{\mathrm{n}_{2}} \mathbf{r}_{\mathrm{i} \mathbf{v}}^{\mathrm{j}} X_{\mathrm{i} \mathbf{V}} \\
& Z_{\mathrm{i}}{ }^{\prime}{ }_{\mathrm{j}}=\sum_{\mathrm{w}=\mathrm{n}_{1}}^{\mathrm{n}_{2}} \mathbf{r}_{\mathrm{i}}^{\mathrm{j}^{\mathrm{j}}{ }_{\mathrm{w}}} \mathrm{X}_{\mathrm{iv}} \mathrm{X}_{\mathrm{i}^{\prime}{ }^{\prime} \mathrm{w}}
\end{aligned}
$$

Y variable to forecast

$\mathrm{X}_{\mathrm{iw}}$ value of $\mathrm{i}^{\text {th }}$ weather variable in $\mathrm{w}^{\text {th }}$ week

$\mathrm{r}_{\mathrm{iw}}$ correlation coefficient between $\mathrm{Y}$ and $\mathrm{X}_{\mathrm{iw}}$

$\mathrm{r}_{\mathrm{i} \text { '' }}$ correlation coefficient between $\mathrm{Y}$ and product of $\mathrm{X}_{\mathrm{iw}}$ and $\mathrm{X}_{\mathrm{i} \text { ' }}$ 
Table 1: Models for forewarning maximum severity of Alternaria blight at different locations

\begin{tabular}{|c|c|c|c|}
\hline Location & Disease & Model & $\begin{array}{l}2 \\
\mathrm{R}\end{array}$ \\
\hline Delhi & Alternaria leaf blight & $\mathrm{Y}=-271.68755+0.031119 * \mathrm{Z}_{121}+0.00891 * \mathrm{Z}_{130}$ & 0.83 \\
\hline Mohanpur & Alternaria pod blight & $\mathrm{Y}=-8.19341+4.38363 * \mathrm{Z}_{11}$ & 0.67 \\
\hline Hisar & Alternaria leaf blight & $\mathrm{Y}=104.22776+0.03814 * \mathrm{Z}_{231}-0.05232 * \mathrm{Z}_{351}+0.17995 * \mathrm{Z} 451$ & 0.88 \\
\hline
\end{tabular}

$\mathrm{Z}_{11}$ is weighted maximum temperature; $\mathrm{Z}_{121}$ is weighted interaction of maximum and minimum temperature; $\mathrm{Z}_{130}$ is unweighted interaction of maximum temperature and morning relative humidity; Z231 is weighted interaction of minimum temperature and morning relative humidity; $Z_{251}$ is weighted interaction of minimum temperature and bright sunshine hours; Z351 is weighted interaction of morning relative humidity and bright sunshine hours; Z451 is weighted interaction of afternoon relative humidity and bright sunshine hours

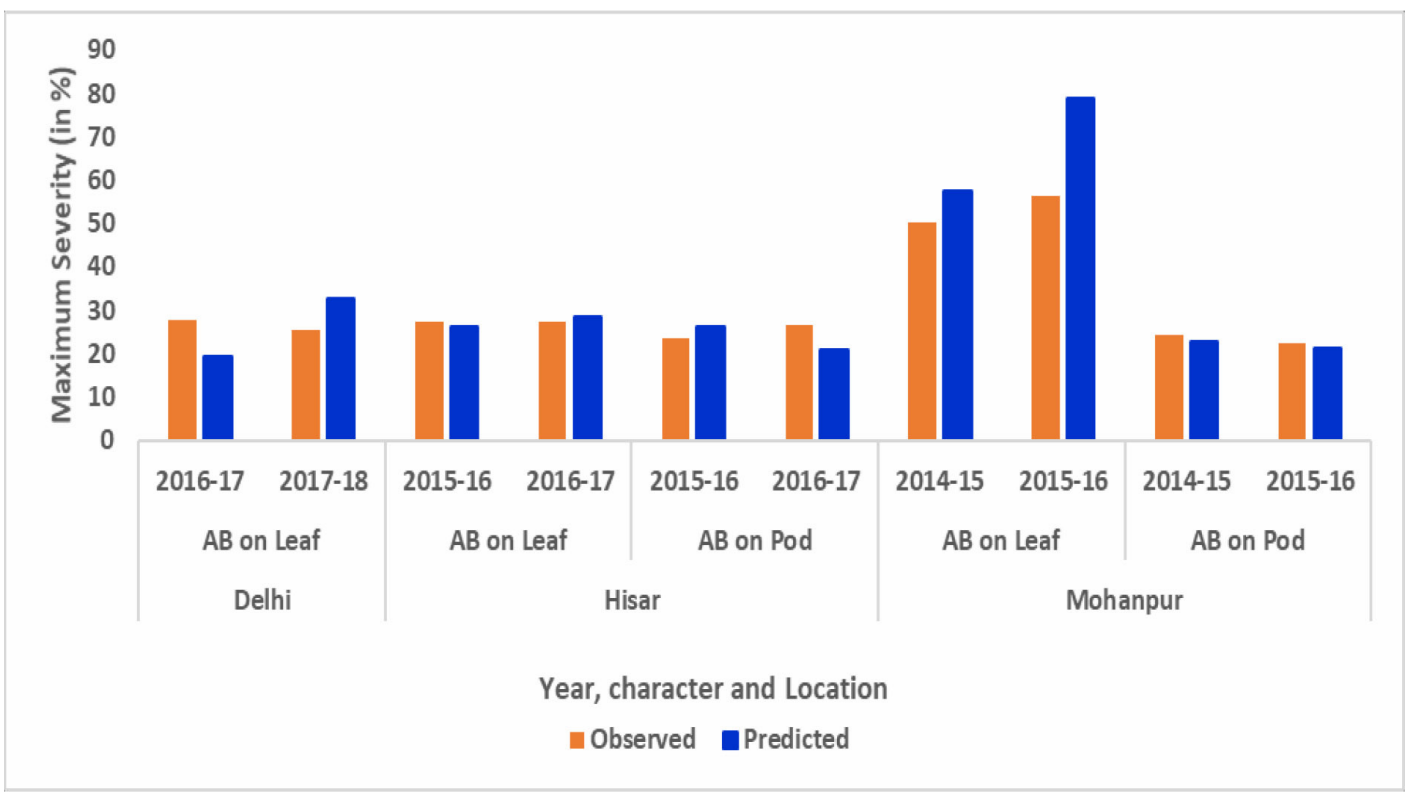

Fig. 1: Observed and forecasted values of maximum Alternaria blight (AB) severity (\%) on leaves and pods in different years at various locations

$\mathrm{p} \quad$ number of weather variables considered

$\mathrm{n}_{1} \quad$ initial week for which weather data were included in the model

$\mathrm{n}_{2}$ final week for which weather data were included in the model

$\varepsilon \quad$ error term

Meteorological variables on maximum and minimum temperature, morning and afternoon relative humidity, and bright sunshine hours ( $\mathrm{T}_{\max }, \mathrm{T}_{\min }, \mathrm{RH}_{\text {morning, }} \mathrm{RH}_{\text {evening }}$ and $\mathrm{BSSH}$ or $\mathrm{X} 1$ to $\mathrm{X} 5$ ) were considered for model development. Partial $\mathrm{F}$ value for each variable in the regression equation at any stage is evaluated and checked for significance. Further, any variable, which provides non- significant partial $\mathrm{F}$ value is removed from the model. The performance evaluation measure based on coefficient of determination $\left(\mathrm{R}^{2}\right)$ was considered in this study. Quantitative models were developed for forewarning of Alternaria blight on leaves and pods of rapeseed-mustard.

\section{RESULTS AND DISCUSSION}

Ecofriendly, viable and sustainable management of Alternaria blight requires knowledge of pathogen-plant interactions in relation to meteorological conditions. Meteorological conditions are important factors in the development of this disease. Meteorological parameter-based indices were generated which were used as explanatory variables. Different meteorological variables viz., minimum and maximum temperature and afternoon relative humidity were identified as critical factors, which significantly affected the development of Alternaria blight of rapeseed-mustard. With a view to predict epidemic status well in advance, models were attempted based on different groups of weeks starting from $45^{\text {th }}$ or $46^{\text {th }}$ standard meteorological week (SMW), were developed by taking meteorological data for the period from 2003-04 to 2016-17 for Hisar (Haryana), 2005-06 to 2015-16 for Mohanpur (West Bengal) and 2006-07 to 2017-18 for Delhi (NCT, Delhi). Models along with coefficients of determination $\left(\mathrm{R}^{2}\right)$ are given in Table 1, which indicate models fitted well because coefficient of 
determination $\left(\mathrm{R}^{2}\right)$ was high in most of the cases. The $\mathrm{R}^{2}$ on leaves was highest at Hisar (0.88) and Mohanpur (0.84), whereas on pods, the coefficient of determination was highest at Mohanpur (0.67) (Table 1). For Alternaria blight severity on leaves, models using meteorological variables up to $2^{\text {nd }}$ SMW at Delhi, Hisar and till $5^{\text {th }}$ SMW for Mohanpur were utilized. Yadav and Brar (2003) reported that temperature and relative humidity appear to be more important factors for the spread of Alternaria blight under South-West Punjab conditions. Our results support these findings.

In Delhi, two meteorological variables i.e., maximum and minimum temperatures with weighted means captured the phenomena of Alternaria blight on leaves satisfactorily (Table 1). The highest $\mathrm{R}^{2}(0.83)$ was for the group of weeks starting from SMW 45 to SMW 2. Weighted index of interaction of maximum and minimum temperatures was found to be important. Observed and predicted values of maximum severity of Alternaria leaf blight at Delhi is shown in Fig. 1. Forecast was very close to observed values in the two years (2016-17 and 2017-18) of validation. Yadav et al. (2010) reported that Alternaria blight progress on leaves was sensitive to minimum and maximum temperature and afternoon relative humidity under New Delhi conditions. In the present study, maximum and minimum temperature with weighted means was found important in influencing maximum severity of Alternaria blight on leaves.

At Hisar, model was attempted by taking weather data for the period 2003-04 to 2016-17. Weighted means of two meteorological variables i.e., minimum temperature and morning relative humidity captured the phenomena fittingly (Table 1). Highest $\mathrm{R}^{2}$ on leaves $(0.88)$ and pods $(0.66)$ were for the group of weeks starting from $45^{\text {th }}$ SMW for both leaves and pods to $2^{\text {nd }}$ SMW and $5^{\text {th }}$ SMW for leaves and pods, respectively. Weighted minimum temperature and bright sunshine hours were also found to be important. For most of the years ( $88 \%$ for leaf and $66 \%$ for pod), the approach has predicted the epidemics of Alternaria leaf and pod blight at Hisar accurately (Fig.1). Forecast was very close to observed values in the two years of validation (2015-16 and 201617).

At Mohanpur, models were developed by taking weather and disease data for the period from 2005-06 to 2015-16. One weather variable i.e., maximum temperature with weighted means captured the phenomena well (Table 1$)$. Highest $\mathrm{R}^{2}$ for leaves $(0.84)$ and pods $(0.67)$ were for the group of weeks starting from $46^{\text {th }}$ SMW to $7^{\text {th }}$ SMW. Weighted maximum temperature was found to be important. For most of the years ( $84 \%$ and $67 \%$ for leaves and pods, respectively), the approach has predicted the epidemics of Alternaria leaf and pod blight at Mohanpur accurately (Fig. 1). Forecast was very close to observed values in the two years of validation (2014-15 and 2015-16).

Validation of forecast made was quite close to actual observations at all the three locations. Forecasts from the models were very close to the observed values in the two years of validation. Kumar (2013) reported that reliable forewarning of Alternaria blight of mustard crop through this approach is possible well in advance. Our results support earlier findings of Kumar (2013). The validation of the models proved the efficiency of the targeted forecasts.
Prediction-based management advisory to farmers could be issued with information for timely application of prescribed fungicidal interventions to manage Alternaria blight. The study reveals that forewarning models for maximum severity of Alternaria blight can be issued at least two to three weeks in advance. Based on this, biointensive management practices of botanicals and bio-agents could be recommended 2-3 weeks in advance (Yadav et al., 2019).

\section{CONCLUSION}

Reliable forewarning of maximum severity of Alternaria blight on leaves and pods in two different varieties of rapeseedmustard is possible through this approach at the three locations (New Delhi, Hisar, Mohanpur). At Delhi, the weighted means of maximum and minimum temperature play an important role in forecasting maximum severity of Alternaria blight on leaves. At Hisar, the weighted means of minimum temperature and morning relative humidity played important role in forecasting maximum severity of Alternaria blight on leaves and pods. At Mohanpur, maximum temperature with weighted means was found the best fit on leaves and pods. Reliable forewarning help the farmers to act appropriately for Alternaria blight management.

\section{ACKNOWLEDGEMENT}

The authors are thankful to The Director, ICAR-National Research Centre for Integrated Pest Management, New Delhi for support and facilities provided during the study. We have utilized the published data of ICAR-AICRP on rapeseed-Mustard specially, Centre of New Delhi, Hisar (Haryana) and Mohanpur (West Bengal). Authors are thankful to agro-meteorological field units of different centres (IARI, New Delhi; CCSHAU, Hisar; BCKV, Mohanpur) for providing the required meteorological data.

Conflict of Interest Statement: The author (s) declares (s) that there is no conflict of interest.

Disclaimer: The contents, opinions and views expressed in the research article published in Journal of Agrometeorology are the views of the authors and do not necessarily reflect the views of the organizations they belong to.

Publisher's Note: The periodical remains neutral with regard to jurisdictional claims in published maps and institutional affiliations.

\section{REFERENCES}

Awasthi, R.P. and Kolte, S.J. (1994). Epidemiological factors in relation to development of prediction of Alternaria blight of rapeseed and mustard. Indian Phytopath., 47: 395- 399.

Chattopadhyay, C., Kolte, S.J. and Waliyar, F. (2015). Diseases of Edible Oilseed Crops. CRC Press Taylor and Francis Group Boca Raton, Florida, p. 443.

Chattopadhyay, N., Kumar, A., Mandal, R.S., Roy, A., Bhattacharya, P.M. and Chowdhury, A.K. (2021). Weather-based models to forecast spot blotch disease of wheat in North Bengal. Indian J. Agric. Sci., 91 (7): 1082-1087. 
Conn, K.L., Tewari, J.P. and Awasthi, R.P. (1990). A disease assessment key for Alternaria black spot in rapeseedmustard. Can. Pl. Dis. Surv., 70:19-22.

Dang, J.K., Kaushik, C.D. and Sangawan, M.S. (1995). Quantitative relationship between Alternaria leaf blight of rapeseedmustard and weather variables. Indian J. Mycol. Pl. Pathol., 25: 184-188.

GoI (Government of India) (2021). $4^{\text {th }}$ Advance Estimates of food grain production for 2020-21. Directorate of Economics and Statistics, Department of Agriculture, Cooperation and Farmers Welfare, Ministry of Agriculture and Farmers Welfare, Govt. of India, New Delhi-110001. https:pib.gov.in > pressreleasepage dated 11 August 2021 by PIB New Delhi.

Kumar, A. (2013). Forewarning models for Alternaria blight in mustard (Brassica juncea) crop. Indian J. Agric. Sci., 81: 116-118.

Kumar, G., Chakravarthy, N.V.K., Kurothe, R.S., Sena, D.R., Tripathi, K.P., Adak, T., Haldar, D. and Anuranjan (2010). Effect of projected climate change on mustard (Brassica juncea). J. Agrometeorol., 12(2): 168-173.

Mahapatra, S. and Das, S. (2014). Effect of meteorological factors on progression of Alternaria blight of mustard and comparison of logistic \& Gompertz growth model in predicting disease severity. Indian Phytopath., 67 (2):155-158.

Singh, H., Kaur, P., Kaur, R., Mukherjee J and Bal, S.K. (2009).
Influence of meteorological parameters on the incidence and development of white rust and Alternaria blight in mustard (Brassica juncea L.) crop in the southwestern region of Punjab. J. Agrometeorol., 11 (Special Issue): 135-142.

Talukdar, D., Deka, R.L. and Dey, U. (2017). Influence of weather factors on incidence of Alternaria blight of rapeseed under the agro-climatic conditions of upper Brahmaputra valley of Assam. J. Agrometeorol., 19(3):277-279.

Yadav, M.S. and Brar, K.S. (2003). Relationship between meteorological factors and incidence of Alternaria blight and white rust of Indian mustard in South-West Punjab. Pl. Dis. Res., 18: 80-82.

Yadav, M.S., Das, D.K. and Yadava, D.K. (2010). Influence of rainfall, temperature and humidity on appearance and development of fungal diseases in Brassica juncea. Pl. Dis. Res., 25: 151-154.

Yadav, M.S., Godika, S., Yadava, D.K., Ahmad, N., Mehta, N., Bhatnagar, K., Agrawal, V.K., Kumar, A., Thomas, L. and Chattopadhyay, C. (2019). Prioritizing components of package of integrated pest management in Indian mustard (Brassica juncea) in India for better economic benefit. Crop Prot., 120: 21-29.

Yadav, M.S., Kumar, A., Godika, S., Ahmad, N., Mehta, N., Yadava, D.K. and Chattopadhyay, C. (2016). Weather-based epidemiological models for Sclerotinia rot of oilseed brassicas for Rajasthan. Indian Phytopath., 69 (4s): 230232, Special issue. 